$\mathrm{DE}$

M E D I C I N A

T R O P I C A L

$\mathrm{DE}$

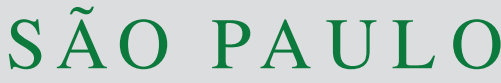

JOURNAL OF THE SÃO PAULO INSTITUTE OF TROPICAL MEDICINE

(1)Guangzhou Center for Disease Control and Prevention, Guangzhou, Popular Republic of China

(2) Guangzhou Medical University,

Guangzhou, Popular Republic of China

(3)University of Hong Kong, Hong Kong,

Popular Republic of China

(4)Yunnan Normal University, Kunming,

Popular Republic of China

${ }^{(5)}$ The Eighth People's Hospital of Guangzhou, Guangzhou, Popular Republic of China

*These first authors contributed equally to this article

Correspondence to: Zhicong-Yang Guangzhou Center for Disease Control and Prevention, Department of Infectious Disease Control and Prevention, № 1, Qide Rd, 510080, Jiahe, Baiyun, Guangzhou, Popular Republic of China

E-mail: gdgzcdc@163.com

Received: 10 September 2017

Accepted: 12 September 2017

\section{Waterfowl as the main reservoir of avian influenza A (H5N6) virus in wet markets}

Guangzhou, September 10, 2017

Dear editor

Recently, we have detected two human cases infected with avian influenza A (H5N6) virus in Guangzhou, Southern China. The first case was a 58-year-old man who was recovering from a hospitalization of more than 50 days $^{1}$. The second case was a 4-year-old girl who eventually died of severe pneumonia ${ }^{2}$. The epidemiological investigation indicated that both patients had history of poultry exposure and they were most likely, infected by the contaminated environment of wet markets ${ }^{1-2}$. To investigate the possible source of exposure, we examined the two wet markets that the two patients used to visit or buy chicken. Environmental samples, including poultry feces, drinking water, swabs from poultry cages, chopping blocks, scalding machines, sewage buckets and from the floor were collected to understand the H5N6 virus contamination in different environmental locations, and caused by different species.

We collected samples from each poultry stall in the two medium-size wet markets in a weekly basis, immediately after reporting of the human cases, over a two-month period. A total of 17 retail stalls were investigated, six of them selling live chickens only, five selling live waterfowls (mostly ducks and geese) only and six selling both. For mixed stalls, the amount of chicken was usually much higher than waterfowl. From 2,081 environmental specimens, 676 were from stalls selling chickens only, 641 from stalls selling waterfowl only and 701 from mixed stalls. As shown in Table 1, 72 specimens tested positive for the H5N6 virus by a reverse transcription polymerase chain reaction (RT-PCR), yielding an overall positive rate of 3.6\%. No H5N6 virus was detected from specimens of stalls selling chickens only, while $2.9 \%$ of specimens were from mixed stalls and $8.1 \%$ of specimens were from stalls selling waterfowl only, with significant increasing detection rates towards samples associated with waterfowl (Chi-square test for trend $\chi^{2}=63.75, \mathrm{P}<0.001$ ). These results suggest that waterfowl is likely to be the main reservoir of the H5N6 virus in the wet market setting, in Guangzhou, Southern China.

Overall, cages and sewages bucket swabs appeared to be most sensitive for detecting the $\mathrm{H} 5 \mathrm{~N} 6$ virus in comparison with other environmental sources, revealing positive rates of $7.8 \%$ and $8.0 \%$, respectively. Regarding samples collected from stalls selling waterfowl only, poultry cages showed a detection rate of $22 \%$, followed by a detection rate of more than $10 \%$ in drinking water and poultry feces. However, no H5N6 positive samples was detected in scalding machines and chopping blocks, as opposed to previous studies on $\mathrm{H} 5 \mathrm{~N} 1$ and $\mathrm{H} 7 \mathrm{~N} 9$ viruses $^{3-5}$. These differences could be explained by the fact that chicken is the main poultry for sale, so we believe that samples from mixed stalls mainly reflected contamination by chicken. Based on these results, surveillance programs should include multiple species and consider drinking water, fecal and cage swabs for monitoring and detecting a broad spectrum of avian influenza viruses.

The higher detection rates of the H5N6 virus in poultry feces, cage and drinking water located in the rear part of the retail stalls, and the relatively low quantity of waterfowl in wet markets may imply a relatively lower exposure to the H5N6 virus by the general population in comparison with the $\mathrm{H} 7 \mathrm{~N} 9$ one. This may partly explain the much lower number of reported H5N6 human cases in China. Sewage buckets 
Table 1 - Influenza A (H5N6) virus detection from different environmental specimens and types of poultry stalls by reverse transcription polymerase chain reaction

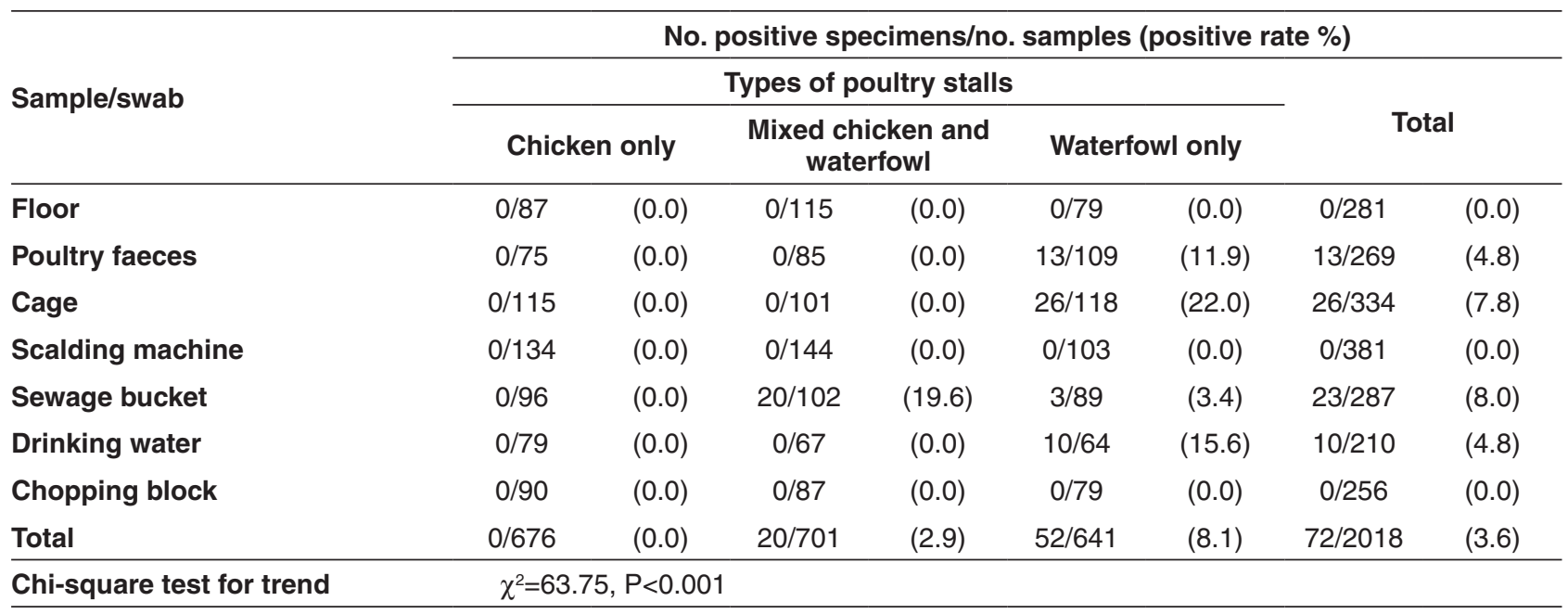

used to hold wasting water temporarily showed relatively high H5N6 detection rate. It is possible that wasting water contaminate the wet market environment, pointing to the need to review and strengthen cleaning and disinfection procedures.

During the investigation period, no dead bird or poultry disease outbreaks were reported although the H5N6 virus was detected in the environment. Furthermore, among the considerable number of samples collected from the stalls selling chickens only, all the positive samples were from stalls selling waterfowl. Considering that H5N6 is highly pathogenic and transmissible from chicken to chicken $^{6}$, these observations indicated that chickens in wet markets were largely H5N6-free. Transmission efficiency was likely to be low from waterfowl to other species in the wet market setting, especially because different species are separately stored. The two H5N6-infected patients are most likely to have acquired infection through waterfowl or the market environment contaminated by them. Apparently, healthy waterfowl may carry and transmit H5N6 viruses silently, from poultry farms to sale markets, subsequently to wet markets, posing a risk to human infections. These findings highlighted that without improved bio-security segregating species, the H5N6 virus might continue to cause human infections without any early alert. Therefore, a systematic surveillance of waterfowl should begin to improve the monitoring of the $\mathrm{H} 5 \mathrm{~N} 6$ virus and the detection of potential human-adapted mutants of the H5N6 virus.

\section{CONFLICT OF INTERESTS}

The authors declare that they have no conflict of interests.

\section{FUNDING}

The project for key medicine discipline construction of Guangzhou municipality was supported by grant $\mathrm{N}^{\circ}$ 2017-2019-07, medical science and technology research of Guangdong province (grant $\mathrm{N}^{\circ} \mathrm{A} 2016056$ ) and Science and Technology Program of Guangzhou (grant $\mathrm{N}^{\circ}$ 21707010451).

\section{AUTHORS CONTRIBUTION}

TL, XT and ZY conceived and designed this study. TL, LEH and HQ analyzed the data, wrote the paper, prepared figures and/or tables. All authors reviewed drafts of the paper.

$$
\begin{array}{r}
\text { Tiegang-Li*1,2 } \\
\text { Lau } \mathrm{EH}^{* 3} \\
\text { Huifeng-Ou } \\
\text { Xiaoping-Tang } \\
\text { Zhicong-Yang }
\end{array}
$$

\section{REFERENCES}

1. Li K, Liu H, Yang Z, Li T, Di B, Chen Z, et al . Clinical and epidemiological characteristics of a patient infected with H5N6 avian influenza A virus. J Clin Virol. 2016;82:20-6.

2. Li T, Ma Y, Li K, Tang X, Wang M, Yang Z. Death of a very young child infected with influenza A (H5N6). J Infect. 2016;73:626-7.

3. Chen Z, Li K, Luo L, Lu E, Yuan J, Liu H, et al. Detection of avian influenza $\mathrm{A}(\mathrm{H} 7 \mathrm{~N} 9)$ virus from live poultry markets in Guangzhou,China: a surveillance report. PLoS One. 2014;9:e107266. 
Waterfowl as the main reservoir of avian influenza A (H5N6) virus in wet markets

4. Indriani R, Samaan G, Gultom A, Loth L, Irianti S, Adjid R, et al. Environmental sampling for avian influenza virus A (H5N1) in live-bird markets, Indonesia. Emerg Infect Dis. 2010;16:1889-95.

5. Yuan J, Lau EH, Li K, Leung YH, Yang Z, Xie C, et al. Effect of live poultry market closure on avian influenza A(H7N9) virus activity in Guangzhou, China, 2014. Emerg Infect Dis. 2015;21:1784-93.

6. Jiao P, Cui J, Song Y, Song H, Zhao Z, Wu S, et al. New reassortant H5N6 highly pathogenic avian influenza viruses in Southern China, 2014. Front Microbiol. 2016;7:754. 